\title{
Rational management of water availability along the phenological stages of Crambe abyssinica Hochst.
}

\author{
Tafarel Victor Colodetti ${ }^{1 *}$, Rogério Rangel Rodrigues ${ }^{4}$, Wagner Nunes Rodrigues ${ }^{1}$, Lima Deleon Martins ${ }^{1}$, \\ Sebastião Vinícius Batista Brinate ${ }^{1}$, Samuel Cola Pizetta ${ }^{4}$, Edvaldo Fialho dos Reis ${ }^{2}$, Marcelo Antonio \\ Tomaz $^{3}$
}

\author{
${ }^{1}$ Programa de Pós-Graduação em Produção Vegetal, Centro de Ciências Agrárias e Engenharias da Universidade \\ Federal do Espírito Santo (CCAE-UFES), Alto Universitário, s/no, Cx Postal 16, Bairro Guararema, Alegre, ES, Brazil \\ ${ }^{2}$ Professor do Departamento de Engenharia Rural, Centro de Ciências Agrárias e Engenharias da Universidade Federal \\ do Espírito Santo (CCAE-UFES), Alegre, ES, Brazil \\ ${ }^{3}$ Professor do Departamento de Agronomia, Centro de Ciências Agrárias e Engenharias da Universidade Federal do \\ Espírito Santo (CCAE-UFES), Alegre, ES, Brazil \\ ${ }^{4}$ Programa de Pós-Graduação Recursos Hídricos em Sistemas Agrícolas, Universidade Federal de Lavras (UFLA), \\ Lavras, MG, Brazil
}

*Corresponding author: tafarelcolodetti@hotmail.com

\section{Abstract}

One of the main environmental stresses that affect the agriculture is the water deficit. There is a constant scientific search to understand the behavior of plants under conditions of drought, aiming to improve the yield of the agricultural species under the effects of this stress. The objective of this study was to determinate the adequate water availability at each stage of the phenological cycle of Crambe abyssinica Hochst, aiming to assist the establishment of irrigation managements with rational water use for this crop. The experiment was conducted in greenhouse to study the influence of levels of water availability along the phenological stages of plants on crambe. A set of growth parameters were measured using a split plot scheme in time (four phenological stages and five levels of available water in the soil) in a completely randomized design and with four replications. The levels of water availability in the soil promoted alterations of growth rate, and the faster growth of Crambe abyssinica were observed with hydric regimen able of provide levels higher than $45 \%$ of available water in the soil; overall, these levels promoted better development of the plants throughout the entire phenological cycle. Increasing the water availability in soil above $45 \%$ was fundamental to obtain higher harvest indexes, with maximum index obtained at $63 \%$ of water available.

Keywords: Crambe; hydric regimen; oilseed; plants of growth; water deficit.

Abbreviations: AW_Available Water; GRH_Growth Rate in Height; GRB_Growth Rate in Biomass; SER_Stem Expansion Rate; RMR_Root Mass Ratio; SMR_Shoot Mass Ratio; HI_Harvest Index.

\section{Introduction}

Crambe (Crambe abyssinica Hochst), from the Brassicaceae family, is a species with great potential for biodiesel production and for inclusion in the energetic matrix as a sustainable fuel source. However, there is still a great need for researches for this crop, especially regarding plant breeding and optimization of crop inputs, such as water and nutrients (Roscoe et al., 2010; Colodetti et al., 2012). The production of energy from oilseeds is an interesting alternative to help to supply the future demands. However, attention must be given to the sustainable use of the croplands, through the improvement of management practices and the efficient use of natural resources (Junginger et al., 2006), especially regarding the rational use of water resources, considering the scenarios of climate change which point to alterations of rainfall patterns.

For crambe crops in Brazil, there is still a lack of scientific information about the water use of the cultivated genotypes as well as the characterization of the water demand along the productive cycle. Therefore, the required water supply is still unknown for each stage of the phenological cycle, and need to be identified to generate a sustainable system with higher water use efficiency and better crop yields.

It is known that water supply is a main factor to allow higher crop yield and to grant the adequate development of the plants. The lack of this resource affects the metabolism, the transport and the translocation of solutes in the plant, the cell turgor, the stomata opening and the expansion of the root system in the soil. Even a small decrease in the water availability may affect the growth, development and, consequently, the crop yield (Taiz and Zeiger, 2013).

One of the main environmental stresses that affect the agriculture is the water deficit. There is a constant scientific 
search to understand the behavior of plants under conditions of drought, aiming to improve the yield of the agricultural species under the effects of this stress (Cattivelli et al., 2008). Some plant species present different capacities to tolerate water deficit, using strategies to keep the metabolic activity even with the evolution of the water restriction (Lawn and Likoswe, 2008). Each species has its own way to behave towards the decrease of the water availability; but, for most, the crop yield is frequently affected by the development of these strategies of drought resistance (Blum, 2005). Therefore, it is greatly important to identify the mechanisms of resistance or tolerance, as well as genotypes or cultivars for which these are expressed in a higher level.

An important tool to generate practical knowledge about the capacity to resist to water deficit is the growth analysis, which helps to identify plants that are able to keep better vigor and yield even when subjected to stressful conditions (Benincasa, 2003). Enlightened by these facts, there is a strong need to intensify the efforts to study the water management in agriculture, identifying the correct moment and amount of water required by the crop, considering the specific needs along the phenological stages and aiming to improve the water use efficiency, as well as rationalizing the use of water sources and lowering production costs.

For two cultivars of rice, it has been verified that water stress during the vegetative growth stage caused a sharp decrease in the leaf expansion and slowed the phenological cycle; for the reproductive stage, it was noticed considerable losses in grain yield (Wopereis et al., 1996). For tomato, the water stress during the flowering caused drastic decrease in morphophysiological aspects, configuring the moment of higher sensibility to water deficit (Brito et al., 2015). For sunflower, the water level of $80 \%$ of the soil capacity of water retention, during the stages between the vegetative growth and start of inflorescence opening, promoted the best growth patterns for the species (Dutra et al., 2012). The research of Silva et al. (2013), also with sunflower, shows that the plants could be irrigated at level of $50 \%$ of the reference evapotranspiration (ETo), without compromising the photosynthetic processes or the plant growth along the development stages; also, it was observed that the irrigation management causing a lesser deficit may result in higher efficiency of water use. For castor oil plant, it is being reported that keeping the water availability at the level of $100 \%$ during the stages of vegetative growth, flowering and fruit formation favored the crop yield and quality of the final product (Silva et al., 2013).

Therefore, the objective of this study was to determinate the adequate water availability at each stage of the phenological cycle of Crambe abyssinica Hochst, aiming to assist the establishment of irrigation managements with rational water use for this crop.

\section{Results and Discussion}

\section{Effect of the available water along the phenological cycle of the crambe}

The interaction between the factors in parcels (water availability) and subparcels (phenological stages) was significant for the parameters of growth rates, both for: height gain, biomass accumulation, stem expansion and biomass partition.
Faster growth in height was observed in the stages of vegetative growth, flowering and grain formation at the levels of $25 \%, 55 \%$ and $70 \%$ of water availability. Overall, the stage of flowering and granation presented the higher GRH, regardless of the water supply. There was no differentiation for the growth rate in height along the stages of emergence and plantlet (Table 1).

With the exception of the growth at level of $10 \%$ of AW, higher daily accumulation of biomass was observed in the stage of vegetative growth, followed by the stage of flowering and grain formation. At $10 \%$ of AW, the higher GRB occurred in the state of flowering and grain formation, and the second higher rate was observed in the state of vegetative growth. At the levels of $10 \%, 25 \%$ and $45 \%$ of AW, no differentiation was observed between the stages of emergence and plantlet, while emergence showed lower GRB at $55 \%$ and $70 \%$ of AW (Table 1).

The highest values of GRH were obtained during the stages of vegetative growth and flowering/grain formation for higher levels of water in soil. Crambe plants present inflorescence of the raceme type, therefore, a rapid growth in extension of the main stem occurs while the new flowers are issued (Roscoe et al., 2010), which contributes to this result. In addition, these phenological stages are characterized by a normal higher growth, both in height and in other related variables (Kmec et al., 1998; Roscoe et al., 2010; Colodetti et al., 2015). However, only during the stage of flowering and grain formation, the values of GRH stood out at the level of $10 \%$ of AW, which is related to the growth of the inflorescences and not from the plant growth as a whole. This finding is in accordance to the behavior of the GRB, for which there was a greater increase in biomass production rate only during the stage of flowering and grain formation for the management with $10 \%$ of AW. For the others levels of AW, the highest values of GRB were obtained during the vegetative growth stage, which was expected.

The higher SER occurred at the stages of vegetative growth for the levels of $45 \%, 55 \%$ and $70 \%$ of $A W$ and also during the emergency at $70 \%$ of AW. For $10 \%$ and $25 \%$ of AW, the SER was higher at the stage of emergence. The slower radial growth of the stem was observed in the stages of flowering and grain formation, regardless of the water supply (Table 1). During these phenological stages, the plants tend to invest their reserves to form flowers and fruits, as these act as stronger metabolic sinks, at the expense of the growth of vegetative structures (Patrick, 1997; Oparka et al., 2000; Taiz and Zeiger, 2013). At this stage, the vegetative growth has already reached the maximum values, showing fully expanded canopies to support the reproductive phase.

The proportion of biomass allocated in the roots was similar among the phenological stages for the conditions of $10 \%$ and $25 \%$ of AW. At levels of $70 \%$, there was higher RMR in the state of vegetative growth. The allocation of biomass in the roots was also higher at the stage of vegetative growth in the level of $55 \%$ of AW, and for the stages of plantlet and vegetative growth in the level of $45 \%$ of AW (Table 1). A greater investment in the root system can be considered a strategy to tolerate the drought, as it provides the plant with a higher capacity to survive such stress, exploring a greater volume of soil (Magalhães et al., 2008; Marschner, 2012; Taiz and Zeiger, 2013). The data obtained for the most stressing conditions provided by this study for 
Table 1. Growth rate in height (GRH), growth rate in biomass (GRB), stem expansion rate (SER), root mass ratio (RMR) and shoot mass ratio (SMR) in stages of the phenological cycle of plants of Crambe abyssinica Hochst for each level of water availability.

\begin{tabular}{|c|c|c|c|c|c|c|}
\hline \multirow{2}{*}{ Trait } & \multirow{2}{*}{ Phenological stage } & \multicolumn{5}{|c|}{ Available water (\%) } \\
\hline & & 10 & 25 & 45 & 55 & 70 \\
\hline \multirow{4}{*}{$\begin{array}{l}\text { GRH } \\
\left(\mathrm{cm} \mathrm{day}^{-1}\right)\end{array}$} & Emergence & $0.69 \mathrm{~b}$ & $0.74 \mathrm{~b}$ & $0.83 \mathrm{c}$ & $1.00 \mathrm{~b}$ & $1.00 \mathrm{~b}$ \\
\hline & Plantlet & $0.55 \mathrm{~b}$ & $0.60 \mathrm{~b}$ & $0.73 \mathrm{c}$ & $0.83 \mathrm{~b}$ & $0.70 \mathrm{~b}$ \\
\hline & Vegetative growth & $0.29 \mathrm{~b}$ & $1.55 \mathrm{a}$ & $1.58 \mathrm{~b}$ & $2.06 \mathrm{a}$ & $2.35 \mathrm{a}$ \\
\hline & Flowering and grain formation & $1.58 \mathrm{a}$ & $1.86 \mathrm{a}$ & $2.48 \mathrm{a}$ & $2.49 \mathrm{a}$ & $2.49 \mathrm{a}$ \\
\hline \multirow{4}{*}{$\begin{array}{l}\text { GRB } \\
\left(\text { g day }^{-1}\right)\end{array}$} & Emergence & $0.01 \mathrm{c}$ & $0.01 \mathrm{c}$ & $0.01 \mathrm{c}$ & $0.01 \mathrm{~d}$ & $0.01 \mathrm{~d}$ \\
\hline & Plantlet & $0.05 \mathrm{c}$ & $0.05 \mathrm{c}$ & $0.05 \mathrm{c}$ & $0.06 \mathrm{c}$ & $0.06 \mathrm{c}$ \\
\hline & Vegetative growth & $0.30 \mathrm{~b}$ & $0.49 \mathrm{a}$ & $0.63 \mathrm{a}$ & $0.65 a$ & $0.69 \mathrm{a}$ \\
\hline & Flowering and grain formation & $0.38 \mathrm{a}$ & $0.38 \mathrm{~b}$ & $0.38 \mathrm{~b}$ & $0.48 \mathrm{~b}$ & $0.52 \mathrm{~b}$ \\
\hline \multirow{4}{*}{$\begin{array}{l}\text { SER } \\
\left(\mathrm{mm} \text { day }^{-1}\right)\end{array}$} & Emergence & $0.21 \mathrm{a}$ & $0.25 \mathrm{a}$ & $0.28 \mathrm{~b}$ & $0.34 \mathrm{~b}$ & $0.34 \mathrm{a}$ \\
\hline & Plantlet & $0.17 a b$ & $0.19 \mathrm{~b}$ & $0.17 \mathrm{c}$ & $0.17 c$ & $0.18 b$ \\
\hline & Vegetative growth & $0.14 \mathrm{~b}$ & $0.21 \mathrm{ab}$ & $0.33 a$ & $0.40 \mathrm{a}$ & $0.38 a$ \\
\hline & Flowering and grain formation & $0.08 c$ & $0.06 \mathrm{c}$ & $0.04 \mathrm{~d}$ & $0.02 \mathrm{~d}$ & $0.02 \mathrm{c}$ \\
\hline \multirow{4}{*}{$\begin{array}{l}\text { RMR } \\
\left(\mathrm{g} \mathrm{g}^{-1}\right)\end{array}$} & Emergence & $0.12 \mathrm{a}$ & $0.13 a$ & $0.13 a b$ & $0.12 \mathrm{ab}$ & $0.12 \mathrm{~b}$ \\
\hline & Plantlet & 0.09 a & $0.12 \mathrm{a}$ & $0.14 \mathrm{a}$ & $0.14 \mathrm{ab}$ & $0.12 b$ \\
\hline & Vegetative growth & $0.11 \mathrm{a}$ & $0.15 a$ & $0.17 \mathrm{a}$ & $0.15 a$ & $0.19 \mathrm{a}$ \\
\hline & Flowering and grain formation & $0.13 \mathrm{a}$ & $0.11 \mathrm{a}$ & $0.09 \mathrm{~b}$ & $0.10 \mathrm{~b}$ & $0.12 b$ \\
\hline \multirow{4}{*}{$\begin{array}{l}\text { SMR } \\
\left(\mathrm{g} \mathrm{g}^{-1}\right)\end{array}$} & Emergence & $0.87 a b$ & $0.86 \mathrm{a}$ & $0.87 a$ & $0.88 \mathrm{a}$ & $0.88 a$ \\
\hline & Plantlet & $0.90 \mathrm{a}$ & $0.87 a$ & $0.85 a$ & $0.86 a$ & $0.87 a$ \\
\hline & Vegetative growth & $0.89 \mathrm{a}$ & $0.85 \mathrm{a}$ & $0.83 a$ & $0.85 a$ & $0.80 \mathrm{~b}$ \\
\hline & Flowering and grain formation & $0.83 \mathrm{~b}$ & $0.79 \mathrm{~b}$ & $0.68 \mathrm{~b}$ & $0.68 \mathrm{~b}$ & $0.67 c$ \\
\hline
\end{tabular}

Means followed by the same letter in the column, for each trait, do not differ by the Tukey test, at $5 \%$ of probability.
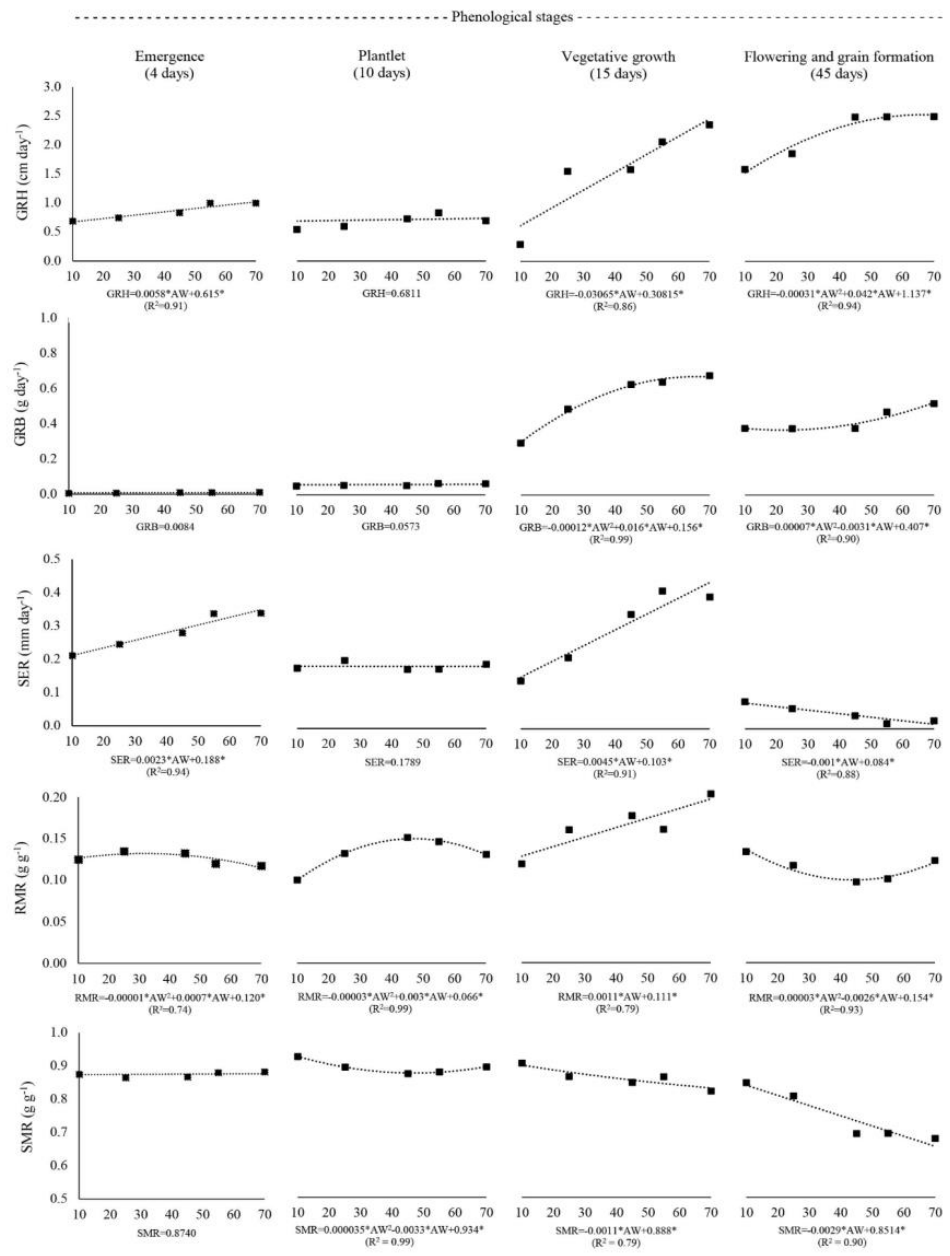

Fig 1. Growth rate in height (GRH), growth rate in biomass (GRB), stem expansion rate (SER), root mass ratio (RMR) and shoot mass ratio (SMR) as function of the water availability, in each stage of the phenological cycle of plants of Crambe abyssinica Hochst. 


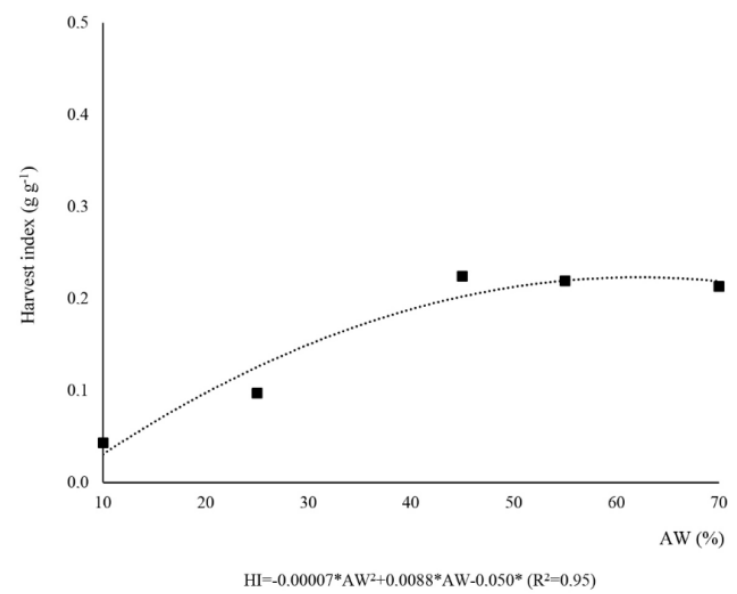

Fig 2. Harvest index as function of the water availability in plants of Crambe abyssinica Hochst.

water availability ( $10 \%$ and $25 \%$ of AW) allowed to study such situation, with plants obtaining higher investment in the root biomass along all the phenological cycle. The investment in the development of roots already from the early stages of emergence showed this effect of the drought over the root growth. With AW over $45 \%$, the overall higher RMR was obtained in the vegetative growth stage, which is characteristic of this phenological stage.

Regarding the SMR, higher biomass being allocated in the aerial part of the plants was observed from the stage of emergence to vegetative growth for the AW ranging from $10 \%$ to $55 \%$, being smaller in the stages of flowering and granation. At $70 \%$ of AW, higher SMR was obtained in the stages of emergence and plantlet, being smaller at the flowering and grain formation (Table 1). This shows that there was a pattern to the allocation of shoot biomass between phenological stages, regardless of AW levels. With the development of reproductive structures and start of the stage of flowering and grain formation, there was a change in SMR, which is due to the allocation of biomass to these new organs. The result is a smaller proportion of the total dry matter being allocated to the leaves and branches as function of the biomass accumulation in roots and fruits, certainly due to these structures being stronger metabolic sinks (Taiz and Zeiger, 2013).

By the regression analyses, it is possible to observe that the water supply had lesser effect over the GRH in the start of the development of the plants, showing no statistical differences along the stages of plantlet. However, the water stress at this moment clearly affected the next stages, as the results obtained in the vegetative growth, flowering and granation started to present differences. The higher level of AW and the level of $68 \%$ of AW caused higher means of GRH for stage of vegetative growth and stage of flowering and grain formation, respectively (Fig. 1). The same behavior was observed for GRB, for which the level of available water didn't cause differences in the stages of emergence and plantlet. However, for stage vegetative growth the level of $67 \%$ of AW caused higher values for daily accumulation of biomass. At flowering and grain formation, the GRB decreased to the level of $22 \%$ of $A W$, increasing up from this point (Fig. 1).

During the stage of most intense growth (vegetative growth stage), it was noted the conditioning caused by the water availability in the soil over the vertical growth of crambe plants. At this stage, when the plant exhibits the most intense growth to be able to support the reproductive stages, there is the period when the plants reach final leafiness. This period is when the leaf area reaches higher values and therefore, the plants become more vulnerable and susceptible to high transpiration rates, as result of the metabolic demand and water potential differences in the soil-plant-atmosphere system (Taiz and Zeiger, 2013). Thus, the water deficit caused greater restrictions on plant growth during this phenological stage, both for the growth in height and production of biomass. However, it was during the flowering and grain formation stage and for GRB that the effects of water availability showed its greater influence over the production of grains. Despite the presence of a minimum point, it is clear the existence of a tendency to show greater responses in the daily production of biomass only above the level of $45 \%$ of AW. It is remarkable that plants could not satisfactory grow and yield grains below the minimum point of the curve, not being agronomically viable to explore the range of AW below this point, as the small growth momentum only is due to a strategy of survival and perpetuation of the species, as shown in Fig. 2 . These results demonstrate the interaction between the growth in height and biomass during the flowering and grain formation stage for higher levels of AW, which are fully interconnected with the higher crop yield of other plant species (Wopereis et al., 1996; Dutra et al., 2012; Silva et al., 2013; Brito et al., 2015). Regarding the SER, a linear expansion was observed with the increase of the level of water availability during the stages of emergence and vegetative growth, with faster growth in conditions of higher supply of water. For the stage of plantlet, the stem expansion was not influenced by the available water in the soil. For flowering and fruit formation, the stem growth decreased linearly with the increase of water supply (Fig. 1). The water supply was extremely important to promote the stem growth, as observed during the emergency and mainly during the vegetative growth stage. The presence of water in adequate levels is fundamental to support the shoot growth, which is required to avoid overturning of plants, since crambe is an herbaceous species (Jaleel et al., 2009; Achten et al., 2010). Also noteworthy is that higher indexes of plant growth were observed in the higher levels of water supply, which is linked 
to the most significant radial expansion of their stems. During the stage of flowering and grain formation, the plant already has the stem fully expanded, starting to aim the metabolic reserved to the growth of flowers and fruits, resulting in reductions in the SER, regardless of the levels of AW in soil. Further decelerations in the SER were observed when the levels of AW increased; that is, during this stage and under such conditions, the plants prioritized the metabolic investment in reproductive structures yet more, instead of the expansion of the stem.

The RMR was effected in a different way by the water supply. A higher proportion of biomass was allocated in the roots at the level of $35 \%$ of AW during the stage of emergence, this same behavior happened in the plantlet stage at $50 \%$ of AW. During the vegetative growth, the higher RMR was obtained when a higher amount of water was supplied in the soil, showing linear increase as function of the AW. For flowering and grain formation, the lower RMR was obtained at level of $43 \%$ of AW, with higher proportion of mass in the root system when the plants were subject to limited water supply or the higher levels of AW (Fig. 1).

Regarding the proportion of dry matter allocated in the aerial part, there weren't differences in response to the water supply along the emergency stage, and there was a small variation in the plantlet stage, for which the level of $47 \%$ of AW promoted the smallest value of SMR. In the stage of vegetative growth, there was linear decrease in the SMR with the increase of the levels of AW. During the flowering and granation, the same effect was observed, however in a higher magnitude (Fig. 1).

Note that the ratio of biomass being allocated in shoots and roots is modulated by the availability of water in all phenological stages. During emergency and seedling stages, the levels of $35 \%$ and $50 \%$ promoted higher mass partition ratios aimed to the development of roots, certainly due to the greater need to explore the soil in the search for water and nutrients, since these AW levels correspond to conditions that are, in a sense, stressing. However, for these same phenological phases, no significant variations were observed for the proportion of mass allocated in the shoot, which may be caused by the natural effort to develop the root system in these conditions. During the stage of vegetative growth, this prioritization has been even more pronounced, with larger increase in RMR due to the increase of AW levels, while SMR decreases linearly. Such prioritization in mass ratio of roots can be explained as a key measure to meet the demands of the reproductive stages. During the flowering and grain formation, this same behavior was observed, with a minimum point at $47 \%$ of AW for RMR and a sharp reduction for SMR due to the increase of AW levels. However, if the results are analyzed for all variables used in this study together, it is noted that above the level of $45 \%$ of AW, the best growth results are observed, which is confirmed and justified by harvest index data to be presented in Fig. 2 .

\section{Effect of the available water over the harvest index of the crambe}

The harvest index of crambe is strongly affected by the water supply in the soil, being $63 \%$ of AW the level that promoted higher proportion of biomass to be allocated in the grains, in relation to the total dry matter of the plant. However, good results of grain production were noticeable over the level of $45 \%$ of AW, while drastic decrease is observed with the limitation of the water supply (Fig. 2).

The harvest index being limited by the low water availability in the soil is justified by the drastic effects caused by water stress in the phenological stages that preceded the harvest.

According to the results for the growth variables discussed previously, note that even in the absence of significant effects in terms of water availability for some phenological stages for a few variables, crambe presented satisfactory and vigorous growth above $45 \%$ of AW. Therefore, it is not recommended submitting the cultivation of this species to water regimen with water supply lower than this level of AW. This fact follows the results obtained for the harvest index, where good results could only be obtained when the vegetative growth of the plant was vigorous enough to support the reproductive phase.

Additionally, despite the higher water supply favoring the growth of vegetative structures in some cases, it did not favor the proportion of fruit on the total plant biomass. Thereby the maintenance of high levels of AW may be unnecessary, since the point of maximum for harvest index was obtained at $63 \%$ of available water in the soil, within the evaluation interval in this study.

Great importance will surely be given to works related to the effects of the water availability over the crop yields. Dramatic reductions have been reported in cultivated species subjected to the effects of water stress, due deleterious actions in biochemical and physiological aspects of plant metabolism, and those can be aggravated when these effects are associated with other stressing factors (Moghadam et al., 2011).

\section{Materials and Methods}

\section{Experimental setup}

The experiment was conducted in greenhouse, located in the experimental area of Centro de Ciências Agrárias e Engenharias of the Universidade Federal do Espírito Santo (CCAE-UFES), in the municipality of Alegre, Espírito Santo state, Brazil, at an altitude of $136 \mathrm{~m}$, with geographic coordinates 2045'2.9”S and 4129'17.5”W (WGS84).

The experiment studied the influence of levels of water availability along the phenological cycle of plants of Crambe abyssinica Hochst, studying a set of growth parameters following a split plot in time scheme, with five levels of water availability (parcel) and four phenological stages (subparcel), in a completely randomized design. Four replications were used and the experimental plot was composed by one plant per pot.

The soil used to fill the pots was classified as Oxisol, collected to a depth of 10 to $30 \mathrm{~cm}$. The chemical and hydrophysical characterization of the soil was performed and fertility of the soil was corrected following the recommendations for essays in controlled environments (Novais et al., 1991). The pots (black plastic, capacity: $8 \mathrm{dm}^{3}$ ) were filled with $7.21 \mathrm{~kg}$ of the fertilized soil.

The seeds of Crambe abyssinica Hochst, from the cultivar FMS Brilhante, were benefited, sterilized with solution of sodium hypochlorite (1\%), washed, dried, packed and stored 
in refrigerator $\left(3^{\circ} \mathrm{C}\right)$, with humidity in the mass at $10-12 \%$, from transport to sowing. Five seeds were sown per pot and the plantlets were thinned after emergence, to allow the growth of only one plant per pot.

\section{Water management}

The hydro-physical analysis was performed according to the methodology proposed by Embrapa (Embrapa, 1997), determining the soil moisture in the field capacity at the tension of $10 \mathrm{kPa}(28.57 \%)$, permanent wilting point at the tension of $1,500 \mathrm{kPa}(13.24 \%)$, soil density $\left(1.03 \mathrm{~kg} \mathrm{dm}^{-3}\right)$, particle density $\left(2.63 \mathrm{~kg} \mathrm{dm}^{-3}\right)$ and total porosity $\left(0.608 \mathrm{~m}^{3}\right.$ $\mathrm{m}^{-3}$ ). The soil presented proportions of $49.1 \%$ of sand, $5.3 \%$ of silt and $45.6 \%$ of clay, according to the granulometric analysis.

The results of the hydro-physical analysis were used to determine the total available water in the soil and the procedures to manage the irrigation followed the methodology described by Bernardo et al. (2006). The water management were established to supply the plants with different levels of water availability. The level of $70 \%$ of available water (AW) was used as standard irrigation for crambe, based in previous results of studies in the same conditions (Colodetti et al., 2015). The irrigation was managed daily, monitoring the water loss through weighting of the pots in analytical balance and allowing the AW to be depleted to $70 \%, 55 \%, 45 \%, 25 \%$ and $10 \%$ of the total $A W$, corresponding to, respectively, 20,44,55, 150, and $300 \mathrm{kPa}$ of water tension in the soil.

The irrigation was performed daily, according to the need, when the soil moisture reached the levels corresponding to each treatment, returning the water level back to the standard level (70\%).

\section{Phenological stages}

Since phenological studies of crambe in Brazilian conditions are still incipient, the only description for phenologic cycle available was used to establish the stages for evaluation. In Brazilian conditions, crambe presents near 90 days of cycle from sowing to harvest. The stage of emergence occurs between 7 and 10 days after sowing. The stage of plantlet takes around 10 days. The stage of vegetative growth takes 15 days. The reproductive stages starts with the flowering, which starts around the $35^{\text {th }}$ and ends around $70^{\text {th }}$ day after sowing. The grain formation occurs from 50 to 80 days (Roscoe et al., 2010), since it is not possible to separate the stages of flowering and grain formation, since they occur concomitantly, they were studied together from $35^{\text {th }}$ to $80^{\text {th }}$ days after sowing.

\section{Evaluated traits}

The plant height, stem diameter and biomass were evaluated for each phenological stage, collecting the experimental plots according to the split plot in time scheme. The plant height was obtained using a ruler, graduated in 0.1 centimeters, measuring the length from soil level to apical meristem. The stem diameter was evaluated with digital caliper (precision: $0.01 \mathrm{~mm}$ ). The collected plants were divided in shoots and roots, separated in paper bags, which were then dried in laboratory oven, with forced air circulation at $60^{\circ} \mathrm{C}$, until constant weight. After drying, the plant materials were weighed on analytical balance (precision: $0.0001 \mathrm{~g}$ ).

The growth rates were calculated based on the temporal variation of the plant height, stem diameter and biomass, resulting in the growth rate in height (GRH), growth rate in biomass (GRB) and stem expansion rate (SER), using the methodology described by Silva et al. (2000).

The biomass of roots and shoots were used to calculate the root mass ratio (RMR) and shoot mass ratio (SMR). After harvest, the fruits were dried in laboratory oven, following the same previous description, and the ratio between the dry matter accumulated in the grains and the total biomass of the plant was used to calculate the harvest index (HI).

\section{Data analysis}

The collected data were subjected to analysis of variance and, according to the presence of significant differences, the means of the phenological stages were studied using the Tukey test ( $5 \%$ of probability) and the means of the levels of water availability were studied using regression analysis $(5 \%$ of probability). The analyses were performed using the statistical software SISVAR (Ferreira, 2011).

\section{Conclusion}

Best growth rates of Crambe abyssinica are observed with hydric regimen able of provide levels higher than $45 \%$ of available water in the soil, since these levels promoted better development of the plants throughout the entire phenological cycle. Increasing the water availability in soil above $45 \%$ is fundamental to obtain higher harvest indixes of the Crambe abyssinica, with maximum index obtained at $63 \%$ of water available.

\section{Acknowledgements}

The authors are grateful to Centro de Ciencias Agrárias e Engenharias of the Universidade Federal do Espírito Santo for supporting this research, providing access to the necessary facilities and laboratories.

\section{References}

Achten WMJ, Maes MH, Reubens B, Mathijs E, Singh VP, Verchot LV, Muys B (2010) Biomass production and allocation in Jatropha curcas L. seedlings under different levels of drought stress. Biomass Bioenerg. 34(5):667-676.

Benincasa MMP (2003) Análise de crescimento de plantas (noções básicas). 2nd edn. FUNEP, Jaboticabal. 41p.

Bernardo S, Soares AA, Mantovani EC (2006) Manual de irrigação. 8th edn. Viçosa, UFV. 625p.

Blum A (2005) Drought resistance, water-use efficiency, and yield potential - are they compatible, dissonant, or mutually exclusive? Aust J Agric Res. 56(11):1159-1168.

Brito MEB, Soares LAA, Lima GS, Sá FVS, Araújo TT, Silva ECB (2015) Growth and formation of biomass of the tomato under water stress in the phenological stages. Irriga. 20(1):139-153.

Cattivelli L, Rizza F, Badeck FW, Mazzucotelli E, Mastrangelo AM, Francia E, Marè C, Tondelli A, Stanca AM (2008) Drought tolerance improvement in crop plants: An 
integrated view from breeding to genomics. Field Crop Res. 105:1-14.

Colodetti TV, Martins LD, Rodrigues WN, Brinate SVB, Tomaz MA (2012) Crambe: general aspects of the agricultural production. Enciclopédia Biosfera. 8(14):258-269.

Colodetti TV, Tomaz MA, Rodrigues WN, Reis EF, Pizetta SC, Brinate SVB, Christo LF, Martins LD, Amaral JFT (2015) Phosphorus fertilization and water management as prevalent factors in the growth of Crambe abyssinica. Am Eurasian J Agric Environ Sci. 15(4):581-587.

Dutra CC, Prado EAF, Paim LR, Scalon SPQ (2012) Development of sunflower plants under different conditions of water supply. Semina: Ci Agrárias. 33(suppl 1):2657-2668.

Embrapa - Empresa Brasileira de Pesquisa Agropecuária (1997) Manual de métodos de análises de solo. 2nd edn. Ministério da Agricultura e do Abastecimento, Rio de Janeiro. 212p.

Ferreira DF (2011) SISVAR: A Computer statistical analysis system. Ciênc agrotec. 35:1039-1042.

Jaleel CA, Manivannan P, Wahid A, Farooq M, Al-Juburi HJ, Somasundaram R, Vam RP (2009) Drought Stress in Plants: A Review on Morphological Characteristics and Pigments Composition. Int J Agr Biol. 11:100-105.

Junginger M, Faaij A, Rosillo-Calle F, Wood J (2006) The growing role of biofuels-opportunities, challenges and pitfalls. Int Sugar J. 108:618-629.

Kmec P, Weiss MJ, Milbrath LR, Schatz BG, Hanzel J, Hanson BK, Eriksmoen ED (1998) Growth analysis of crambe. Crop Science. 38:108-112.

Lawn RJ, Likoswe AA (2008) Genotypic differences in leaf area maintenance contribute to differences in recovery from water stress in soybean. Aust J Agric Res. 59:10751085.

Magalhães Filho JR, Amaral LR, Machado DFSP, Medina CL, Machado EC (2008) Water deficit, gas exchange and root growth in 'Valencia' orange tree budded on two rootstocks. Bragantia. 67(1):75-82.

Marschner H (2012) Mineral nutrition of higher plants. 3rd edn. Academic Press, London. 672p.
Moghadam HRT, Zahedi H, Ghooshchi F (2011) Oil quality of canola cultivars in response to water stress and super absorbent polymer application. Pesqui Agropecu Trop. 41(4):579-586.

Novais RF, Neves JCL, Barros NF (1991) Ensaio em ambiente controlado. In: Oliveira AJ, Garrido WE, Araújo JD, Lourenço $S$ (ed) Métodos de pesquisa em fertilidade do solo. Embrapa/SAE, Brasília. p.189-254.

Oparka KJ, Santa Cruz S (2000) The great escape: phloem transport and unloading of macromolecules. Annu Rev Plant Physiol Plant Mol Biol. 51:323-347.

Patrick JW (1997) Phloem unloading: sieve element unloading and post-sieve element transport. Annu Rev Plant Physiol Plant Mol Biol. 48:191-222.

Roscoe R, Pitol C, Broch DL (2010) Necessidades climáticas e ciclo cultural. In: Pitol C, Broch DL, Roscoe R (ed) Tecnologia e produção: crambe 2010. Fundação MS, Maracajú. p.07-09.

Silva ARA, Bezerra FML, Lacerda CF, Pereira Filho JV, Freitas CAS (2013) Gas exchange in sunflower plants subjected to water deficit at different stages of growth. Rev Ciênc Agron. 44(1):86-93.

Silva JEB, Guerra HOC, Lacerda RD, Barros Júnior G, Formiga LA (2013) Production and fruit quality of castor bean in seeding and regrowth under phenological water stress. $R$ Bras Eng Agríc Ambiental. 17(11):1167-1172.

Silva LC, Beltrão NEM, Amorim Neto MS (2000) Análise de crescimento de comunidades vegetais. Embrapa/CNPA, Campina Grande. 46p.

Souza ADV, Fávaro SP, Ítavo LC, Roscoe R (2009) Chemical characterization of seeds and presscakes of physic nut, radish and crambe. Pesqui Agropec Bras. 44(10):13281335.

Taiz L, Zeiger E (2013) Fisiologia de plantas. 5th edn. Artmed, Porto Alegre. 954p.

Wopereis MCS, Kropff MJ, Maligaya AR, Tuong TP (1996) Drought-stress responses of two lowland rice cultivars to soil water status. Field Crop Res. 46:21-39. 